\title{
Using Audio-Logs for Analyzing the Development of a Common Operational Picture in Multi-agency Emergency Response
}

\author{
Kristine Steen-Tveit \\ Centre for Integrated Emergency \\ Management \\ Dept. of Information Systems, \\ University of Agder, Norway \\ kristine.steen-tveit@uia.no
}

\author{
Jaziar Radianti \\ Centre for Integrated Emergency \\ Management \\ Dept. of Information Systems, \\ University of Agder, Norway \\ jaziar.radianti@uia.no
}

\author{
Bjørn Erik Munkvold \\ Centre for Integrated Emergency \\ Management \\ Dept. of Information Systems, \\ University of Agder, Norway \\ bjorn.e.munkvold@uia.no
}

\begin{abstract}
Multi-agency emergency response requires effective communication and collaboration for building and maintaining a common operational picture. Full-scale exercises are shown to be effective for learning, and for training the collaborative skills needed. This paper presents a methodology for the analysis of real-time communication for building the common operational picture, using audio-logs. The analysis of the audio-logs provides insights for both practitioners and researchers in the emergency management domain concerning the dynamics of inter-agency collaboration and information exchanges when responding to emergencies. Coding and categorizing of audio-log-based information exchanges among multi-agency stakeholders were applied based on a full-scale emergency exercise on multiple terror actions. The results show that the methodology can contribute to analyzing the development of a common operational picture, supplementing existing methods for evaluation of fullscale emergency exercises and real events.
\end{abstract}

\section{Introduction}

In large scale emergency events involving multiagency collaboration several factors need to be in place, i.e. common communication tools, the establishment of a common operational picture (COP), mutual trust and respect, as well as awareness about own and other Emergency Management Services' (EMS) responsibilities and tasks. To make expedient use of those factors, it is important that the emergency stakeholders possess the knowledge of the systems and capabilities to use them to solve the tasks [1]. Yet, without the key information concerning the situation, cooperation is not enough to make a response operation more efficient [2]. Such operations typically deal with heterogeneous information needs, processes/ structures, goals, resources, technology and other features within the involved organizations [3]. Despite these heterogeneities, the key goal for all actors is to collaborate to save lives and limit damage.

Worldwide, mass causality incidents have a huge impact on communities, both in terms of human suffering and the economy. One example is the terror attacks in Norway on $22^{\text {nd }}$ of July 2011, where 77 people, mostly very young, were killed and 260 people were injured in two planned attacks. The commissionreport concluded that there were several blameworthy conditions and a significant need for changes. For instance, the report stated that some of the failures were due to impaired ability to recognize risk and that learning from exercises had been deficient, furthermore, the establishment of situational awareness (SA) and a COP during the response operation was insufficient [4]. Learning from previous decisions, actions and incidents must be practiced and evaluated through full-scale regional exercises to enhance the EMS' capabilities to handle mass causality incident operations [5].

Evaluation is a method for generating new knowledge and understanding in a certain setting, and by utilizing the results of the evaluation, the consequences can be changed in the affected organizations [6] As Weiss [7] states: «the overall aim of evaluations is to assist people and organizations to improve their plans, policies and practices». In multi-agency emergency management, the different involved actors are aiming to achieve a collective perception, but they are likely to transfer their own vision to the situation, based on their own professional standpoint [8]. Therefore, in an exercise involving several decision-makers, effective evaluation is an issue because different decision-makers operate with different understanding and knowledge about the situation [9]. This reflects the difficulty of objective evaluation of full-scale exercises [10] and the need for an efficient method for evaluation is essential to be able to defend the resource-and economic aspect of large exercises. The visualization of information in most evaluations relies on textual sources (such as reports) and interviews. The lack of real-time communication makes it difficult to gain the detailed information being

URI: https://hdl.handle.net/10125/63813 
exchanged, and access to this material will contribute to strengthen the evaluation's results.

This paper extending previous findings [11], and aims to provide an analysis methodology for evaluating the COP established during a full-scale exercise, through post hoc analysis of the inter-agency communication using audio-logs. One of the advantages of this proposed approach is that the individual actor's narrative (which is likely to be affected by their own view) can be compared to the actual communication during the event, to inform the post even debriefing. Thus, the method can provide an important contribution to existing evaluation methods. This approach offers a foundation for common discussion on important features and the outcome of the interactions. Moreover, the proposed categorization framework of the exchanged information provides the opportunity to evaluate the COP.

To demonstrate the usefulness of the approach, we conducted a temporal analysis of a full-scale exercise involving a multiple terror attack scenario. The analysis shows the changes in the multi-agency interactions and information being exchanged from time to time, reflecting the communication patterns, interactions and the importance of particular communications in different stages of the event. By investigating communication patterns and bottlenecks, the potential for improvement is possible [12].

\section{Theoretical Framework}

Situational Awareness: Disaster management is an active process over time, which gradually changes as the situation develops, and the signals change [13]. Disaster response systems must be able to handle the complexity of the emergency environment and include the fact that a variety of agencies will be involved in making complex decisions during the operation [14].

During these emergency operations, situational awareness (SA) plays a critical role due to performance and error prevention [15]. Therefore, it is necessary to establish SA during emergency management. The theory of SA is the foundation for a large number of studies on dynamic human decision-making in several domains [e.g. 16, 17-19]. With evolving technology support humans are able to act more effectively in decision-making when operating in dynamic systems [20]. SA in multi-agency operations includes complex cognitive components. While analysis of the audio-log from the response operation does not cover the actors' cognitive processes, the communication can reveal the state of SA in different stages of the operation. Moreover, SA is an important component for all actors involved for both creating and maintaining a COP (see figure 1). The SA theory is used by a number of other studies, for example as a framework for defining emergency stages by taking the available information into account [21] and how individuals develop different levels of SA by conducting a SA requirements - and resource analysis [22].

Endsley [23] defines three different levels of SA:(1) perceiving the elements in the environment, (2) comprehending the current situation, and (3) projecting the future status of the situation. The first level is crucial for the actor to achieve SA because it involves the critical cues/information needs, and further, it forms the basis for the construction of the two next levels. The actors' achievement of SA level 2 and 3 consists of important information to share, for instance, level 2 is the foundation for actions, and level 3 for action planning. This is also related to the operation's goals, and in multi-agency emergency operations, such as in mass causality incidents, the actors interact interdependently toward a common goal [15]. The involved agencies must collaborate to reach the shared goals, and the critical information should not been kept individually or internally in the agencies [24]. The case to be presented in this paper clearly demonstrates the importance of SA within the agencies for contributing to a COP among all the involved stakeholders (figure 1). Without a sufficient SA the contribution to a COP will be incomplete.

Common Operational Picture: Collaboration and coordination are crucial factors for success in crisis management [e.g. 3, 25, 26]. Several studies and retrospective analysis point to challenges related to coordination in multi-agency emergency management [27-31]. Information sharing is a significant component in the collaborating process and the reliability of the shared information is crucial in intensive operations [12]. There are several bottlenecks due to information sharing among multiple agencies in mass causality incidents, and a major reason seems to be the nature of the incident itself. Several studies point to the complexity, the dynamics and the unpredictable aspect

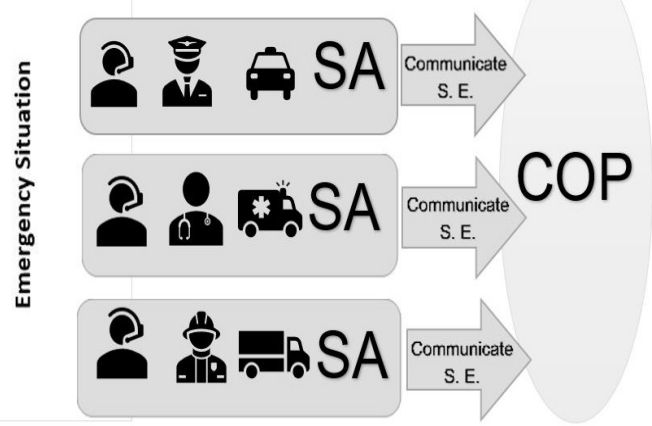

Figure 1 Agencies' SA and communication of shared elements (SE) to create a COP 
of the environment [e.g. 20,28] where collaboration needs to be unfolded.

The EMS needs a collection of relevant and verified information from different sources in the environment, and further to share this with the collaborating EMS. This includes both static and dynamic features of the environment [32], such as location, incident type, number of victims and threats.

The different agencies involved, representing different professional disciplines, will have some SA requirements that are internal and specific for the agency`s goal (see figure 1). However, in collaboration processes, many of their actions will be interdependent and they will have shared goals with the other involved agencies and thus shared SA requirements [15]. In communication that aims to achieve a COP, it is important for all the involved parties to understand information not only based on their own view but also what is crucial for the collaborating agencies.

This requires knowledge of each other's key elements, such as information needs, goals, expectations, responsibilities, resources, capabilities and procedures to achieve effective cooperation [33, 34]. Agencies with different tasks and goals might emphasize the data that mostly concern themselves [35], and absence of knowledge on these key elements can create an information overload or lack of information caused by ignorance or inability to determine necessary information to share [3]

In addition, the agencies utilize different terminologies [36]. Using different terminologies among the agencies addressing the same concepts and events can hinder the establishment of the COP. Heterogeneous awareness about different terms is a problem among emergency stakeholders [37]. An overview of crisis vocabularies are not always present, and when they are, they are distributed on diverse repositories designed differently and not harmonized across agencies [38]. It seems to be necessary with more coordination on terminology management [39] and the task-critical information must be exchanged by using harmonized terminology to build and maintain a COP.

The majority of the emergency management information systems facilitate only information sharing and do not emphasize the collaboration process [21]. The fact that the actors have different perceptions of information [40] implies that even if the information system provides a solid foundation for communication and information sharing, the lack of a standardized framework [21] for the collaboration process may result in ineffective processes for communication and cooperation.

The characteristics of a COP are relevant operational information across agencies [41]. Thus, to create a COP the communication must be structured to provide the involved agencies with accurate, timely and prompt information. The time aspect concerns several elements; sharing information in the least possible time because of the time-paced situation [42], sharing information in the different stages of the operation, and the continuous communication process for the involved actors' maintenance of a COP. Several studies underpin the importance of this upkeeping of a COP, and that it is a necessary component for the emergency operation to be effective [e.g. 41, 43, 44].

One must consider that complete SA is not possible in any emergency operation [40], but each agency involved will focus on collecting the task-oriented critical cues that provide the highest possible SA. Furthermore, in multi-agency operations, the individual agencies have a responsibility to create a COP together with the collaborative agencies. In addition to common SA elements, the COP is an accumulation of important information elements that are selected in different categories such as the different organizational actions, prognosis and perceptions [43].

The COP can be communicated by technology such as Geographical information systems (GIS), by providing a display of relevant operational information, such as positions, infrastructure and different resources using custom symbols [41]. Many EMS do not use the same GIS interface and only operate with tools supporting verbal communication in the collaboration process. Regardless, the communication of shared elements must be conducted in an appropriate way, using a standardized framework, definitions and common terminology [12] and symbols for successfully creating a COP (see figure 1).

Building a COP among multi-agencies is a skill that is focused as an important part of exercises in emergency management, and the inclusion of collaborative elements offer participants perceived learning [45]. Conducting a full-scale exercise is demanding both in terms of costs and resources required. Several factors need to be considered, such as the so-called "infallibility behavior" that refers to the participants' effort to do their absolute best to make an impression. Nevertheless, if a culture for learning exists, the participants are willing to reveal their weaknesses for the learning outcome's sake [25]. The outcomes after emergency management exercises offer useful learning for the participants [46]. However, a study of three collaboration exercises involving the police, fire and ambulance services conducted in Sweden [47] revealed that the perceived impact on actual emergency work was moderate. The learning outcome did not include the collaborating EMS' way of communication and prioritizing, thus the collaboration elements in exercises should be strengthened. An important step in this would be a common understanding among the involved 
agencies concerning basic concepts, structures and processes, thus knowing each other's operational modes [12].

Based on the literature reviewed earlier, the following table summarizes important features for EMS to maintain a COP in complex emergency operations:

\section{Table 1 Important features for a COP}

\begin{tabular}{|l|l|}
\hline 1 & $\begin{array}{l}\text { Creation and maintenance of different levels of SA } \\
\text { within the involved agencies. }\end{array}$ \\
\hline 2 & $\begin{array}{l}\text { Knowledge of each other`s operational modus, such } \\
\text { as information needs, goals, capabilities, processes } \\
\text { and resources. }\end{array}$ \\
\hline 3 & $\begin{array}{l}\text { Effective and time-specific communication of } \\
\text { important static and dynamic environmental } \\
\text { features, shared elements and common critical cues. }\end{array}$ \\
\hline 5 & $\begin{array}{l}\text { Harmonized terminology, both in vocabulary and } \\
\text { software symbols. }\end{array}$ \\
\hline 5 & $\begin{array}{l}\text { Sharing useful comprehension of the current } \\
\text { situation and actions/action planning important for } \\
\text { the collaboration. }\end{array}$ \\
\hline 6 & $\begin{array}{l}\text { Follow a standardized framework for } \\
\text { communication to avoid useless information and } \\
\text { information overload. }\end{array}$ \\
\hline
\end{tabular}

\section{Methodology}

The empirical foundation for this paper is a case study of a full-scale regional exercise involving multiple terror incidents in southern Norway. The exercise was designed to train the cooperation among stakeholders in the field, but each involved EMS also had several internal sub-goals to train. Multiple qualitative methods were used, combining observation, audio-log analysis and validation with stakeholders after the exercise to clarify vague results. Using the audio-log as a methodology for post-hoc analysis allows the actual communication combined with the event timeline to reveal the "live image" of the communication among the collaborating stakeholders. This serves as an important supplement to traditional retrospective interviews and textual analysis, and it addresses the need for detailed information being exchanged during emergency operations.

\subsection{Scenario}

The exercise involved three interrelated incidents occurring almost simultaneously. The scenario was built on a terror attack where a single terrorist hijacked a bus with 20 student passengers at a school a few kilometers from the city center. The situation developed and required a multi-agency operation involving the police, fire and health services. The bus was not stopped and drove away from the event site. About 10 minutes later a traffic accident with an unknown number of human injuries occurred in a harbor intersection. The police Command and Control Centre (CCC) then issued a triple-alert (alerting all involved CCCs in a conference phone call) and provided a common update on the new incident for building a common operational picture.

Yet another incident was alerted after 5 minutes, from a public witness reporting that the hijacked bus had driven into a crowd attending an open concert by the waterfront of the city center. A large unknown number of people was injured both on land and in the water, creating a chaotic situation. The police CCC updated the fire and health services on the new incident and informed about the caller's perception of an intentional event (the act of terror). The police defined the situation as an ongoing life-threatening violence operation, which activates specific procedures for all agencies involved. Furthermore, this situation required the involvement of more organizations such as the Sea Rescue, the affected municipality, Volunteer organizations and the Civil Defence. An assembly place for injured and deceased was organized, and incident commanders for police, fire and health services were appointed. Evacuation of the area, the establishment of a next of kin center and communication with media were some of the important tasks that unfolded in the next 30 minutes of the exercise. The entire exercise had a timeframe of approximately 5 hours, with the active part lasting for about 3 hours.

\subsection{Observation}

The observation was carried out by two authors, whereby one was observing the work in a $\mathrm{CCC}$ and the other was present at the most resource-intensive emergency site. i.e. the last incident by the city center waterfront. In the CCC notes were taken while observing the operation as well as questions asked when something was perceived as unclear. It should be noted that the first author has practical experience from emergency dispatching and therefore holds some basic knowledge in this area. The on-site observation involved observing the different emergency personnel's operation from a spot with a good overview, taking several pictures. Some questions were posed to the involved organizers and actors after the exercise both for collecting their opinions and to clarify uncertainties on the results. Stakeholders from all agencies provided comments.

\subsection{Audio-log from the inter-agency call group}

EMS in Norway are using the Norwegian Public Safety Network (NPSN) as a common platform for collaborative communication. The technology is built on the TETRA- standard (TErrestrial Trunked RAdio). 
This infrastructure provides secure communication in coverage, capacity and voice quality. The NPSN gives the users an opportunity to communicate in call groups across agencies and geographical areas. The first responder agencies in Norway use the NPSN as a key tool in their daily operations. In this paper, the audio-log studied is an inter-agency call group reserved only for first responders, named BAPS (fire-police-acute medicine cooperation). Common regulations for using the NPSN [48] provides a set of guidelines for user identification signals, when different functionalities should be used, definitions related to the NPSN and plain-radio language checks for group communication. The guidelines for use of the NPSN [49] underpin the importance of regular user exercises to secure proper practice and utilization of the functionalities.

The audio-log consists of communication between operative units and dispatchers from the police, fire and health (ambulance) services. The communication mainly originates from the following six actors; (1) Emergency dispatcher from Police CCC, (2) Emergency dispatcher from Fire CCC, (3) Emergency dispatcher from Health CCC (4) Incident Commander Coordination Point, Police officer, (5) Incident Commander Health/ ambulance personnel, (6) Incident Commander Fire and rescue services. Additionally, operative units from all mentioned services occasionally communicated in the inter-agency call group. There are other options for communication in the NPSN, for instance, the stakeholders can communicate in agency-internal call groups or in one-to-one conversations during the operation. The studied interagency call-group functions as a collaboration channel for the first responders, and it is required for all actors in these agencies to continually listen to this group.

The audio-log had several tracks, i.e. the recording of the communication was divided into several audio files in the record system and consisted of a total of 4,25 hours. The tracks show the actual timeline with both silence and messages, and all tracks were transcribed to ensure the completeness of all messages. All sequences of the events were further reconstructed into a complete dataset and systematized with the following information; 1) the origin of the information; 2) the recipient of the information, and 3) the information content. The dataset was also triangulated with the realtime logs documented by the police during the drill. The authors discussed and classified the messages into several categories (Table 2). The categorization used an inductive method and was developed gradually through classification and reclassification based on the content of the messages until a stable, unique category framework emerged. The process narrowed down the original 22 categories into 14 categories, as listed in Table 2 . The categories aim to be sufficiently specific to reflect the content of the messages, but still also generic enough to to be used in other similar cases [50]. Some of the categories relate to the important features of a COP (Table 1), e.g., COP feature number 1, 2 and 3 in Table 1 are mirrored in the "Situation Report" and "Location" categories (Table 2) as the actors shared their SA and provided the collaborative agencies with important information from the operation and environment. The categories "Action", "action plan" and "request" are related to feature number 5 . Feature 4 and 6 are related to "report barriers", as different terminology and information overload can represent hindrances in the task execution. In brief, analyzing the features of a COP can be used for systematic learning after exercises, especially as provided by audio-log post-hoc analysis of real-time communication.

Table 2: Communication Exchange Categories

\begin{tabular}{|c|c|}
\hline Categories & $\begin{array}{c}\text { Coverage } \\
\end{array}$ \\
\hline $\begin{array}{l}\text { Situation } \\
\text { Reports }\end{array}$ & $\begin{array}{l}\text { Information flow that involves new and } \\
\text { updated information regarding the } \\
\text { emergency. }\end{array}$ \\
\hline Confirmation & $\begin{array}{l}\text { Statements that express the agencies' } \\
\text { acknowledgment (heard, known, } \\
\text { understood) information or actions. }\end{array}$ \\
\hline Action Plan & $\begin{array}{l}\text { Statements which imply the agencies } \\
\text { 'plan for action in order to respond to } \\
\text { the current state. }\end{array}$ \\
\hline Request & $\begin{array}{l}\text { Request for updated information, } \\
\text { resources or support }\end{array}$ \\
\hline Action & Actions taken and reported in BAPS \\
\hline Location & $\begin{array}{l}\text { Providing or confirming a current } \\
\text { location or being in a wrong location }\end{array}$ \\
\hline Contacting & $\begin{array}{l}\text { The actor tries to contact one or several } \\
\text { actors }\end{array}$ \\
\hline No Answer & $\begin{array}{l}\text { When the addressed actor(s) did not } \\
\text { reply to the contact request }\end{array}$ \\
\hline $\begin{array}{l}\text { Offer } \\
\text { resources }\end{array}$ & $\begin{array}{l}\text { When one agency offers resources } \\
\text { relative to the situation }\end{array}$ \\
\hline $\begin{array}{l}\text { New } \\
\text { Emergency } \\
\text { event }\end{array}$ & $\begin{array}{l}\text { Notifications on new emergency events } \\
\text { relative to the operation }\end{array}$ \\
\hline $\begin{array}{l}\text { Common } \\
\text { Understanding }\end{array}$ & $\begin{array}{l}\text { Information on the situation and all } \\
\text { involved agencies confirm that they } \\
\text { have received and understood. }\end{array}$ \\
\hline $\begin{array}{l}\text { Report } \\
\text { barriers }\end{array}$ & $\begin{array}{l}\text { Reports of barriers when performing } \\
\text { tasks, such as missing equipment or } \\
\text { conflicts with other involved parties. }\end{array}$ \\
\hline Error & $\begin{array}{l}\text { Disruptions in the call group (such as } \\
\text { human mistakes). }\end{array}$ \\
\hline $\begin{array}{l}\text { Information } \\
\text { Mismatch }\end{array}$ & $\begin{array}{l}\text { When actors have different SA in a } \\
\text { specific situation. }\end{array}$ \\
\hline
\end{tabular}

\section{Results}

In this section, we present the results of our communication analysis. No actual contents of the 
communication in the audio-logs are presented, to protect the stakeholder's privacy.

However, both the timeline and actual conversations have been documented, allowing us to trace back the actual messages. Some of the stakeholder's comments are cited as validation for the results. It is necessary to consider several issues regarding these comments. For instance, each comment mirror one person's opinion and is likely influenced by post-hoc rationalization [51].

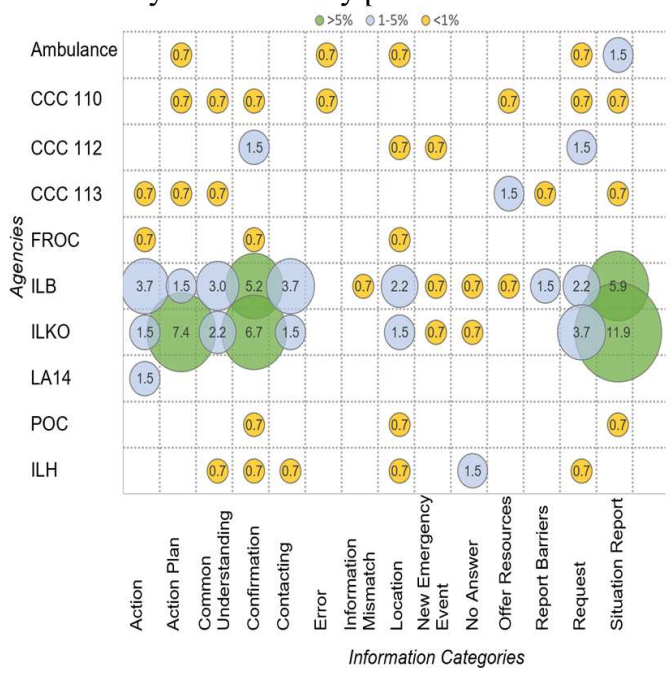

Figure 2 Information being exchanged by each agency (\%)

Figure 2 presents an overview of the percentage of categories exchanged by the agencies, whereas the total number of messages is 134 . As can be seen, the figure depicts that ILKO and ILB (see table 3 explaining abbreviations) were the most active agencies, especially on communicating "action plan", which was frequently followed by "confirmation" in a number of messages

\section{Table 3: List of Abbreviations}

\begin{tabular}{|l|l|}
\hline Abbreviation & \multicolumn{1}{|c|}{ Description } \\
\hline BAPS & $\begin{array}{l}\text { Fire, health }- \text { and police services inter- } \\
\text { agency call group }\end{array}$ \\
\hline ILKO & Incident commander Point, Police officer \\
\hline ILB & $\begin{array}{l}\text { Incident Commander, Fire and rescue } \\
\text { personnel }\end{array}$ \\
\hline ILH & $\begin{array}{l}\text { Incident Commander, Health, ambulance } \\
\text { personnel. }\end{array}$ \\
\hline LA14 & Ambulance Helicopter \\
\hline POC & Police Operative Car \\
\hline FROC & Fire-and rescue Operative Car \\
\hline Ambulance & Ambulance team \\
\hline CCC 110 & $\begin{array}{l}\text { Command and Control Center, Fire and } \\
\text { rescue }\end{array}$ \\
\hline CCC 112 & $\begin{array}{l}\text { Command and Control Center, } \\
\text { Police Services }\end{array}$ \\
\hline CCC 113 & $\begin{array}{l}\text { Command and Control Center, } \\
\text { Health services }\end{array}$ \\
\hline NPSN & Norwegian Public Safety Network \\
\hline
\end{tabular}

These two organizations played a key role in reporting situations, especially ILKO. In this terror act case, the police have the superior responsibility of the operation. Thus, it is natural that they received most information from their $\mathrm{CCC}$ and took responsibility for building a COP. For ILB, this situation was resourceintensive, requiring the mobilization of a truck (to stop an uncontrolled bus) and divers (for rescuing victims in the water). The ambulance personnel carried out the treatment of the victims and would "not spend much time on communication in BAPS" [stakeholder comment].

To analyze the development of the inter-agency interactions when building the COP, we developed chord diagrams. The diagrams show the communication flow among the agencies, of which the chord runs from the originator agency to the recipient agency, furthermore, the more volume in the chord, the higher number of messages. Information categories being exchanged are presented as bar charts. The scenario guidelines and messages in the audio-log revealed that the crisis could be divided into three phases: the alert phase (when the three CCCs alerted the different response teams), the escalation phase (when the operative units are starting to comprehend the crisis), and response (when all involved agencies are managing the crisis).
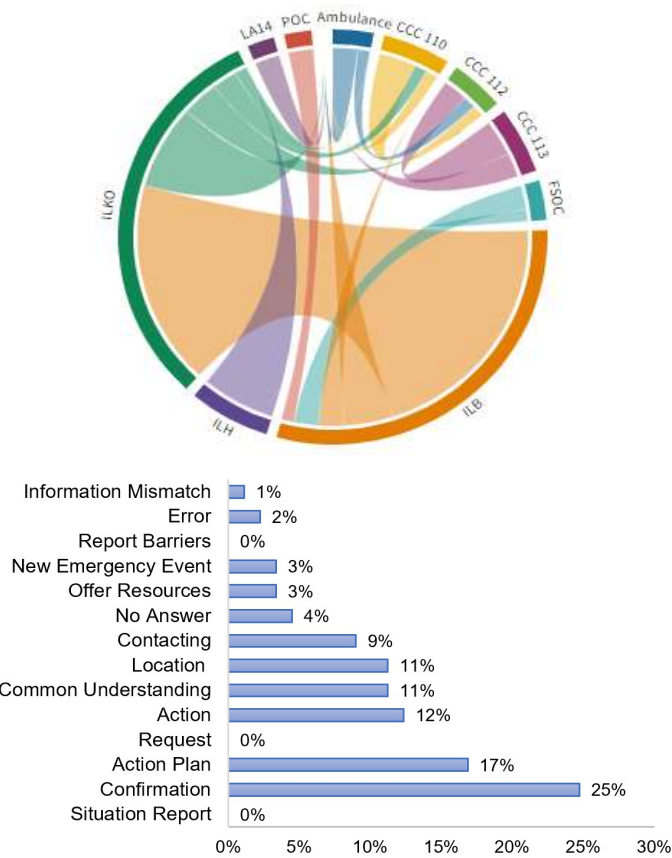

Figure 3 Multi-agency interactions (upper) and information being exchanged (bottom), 10:00-10:30 


\section{Alert phase (10:00-10:30)}

In this phase the number of messages was at the highest with 88 messages being exchanged. ILKO and ILB communicated with each other with a considerable higher frequency than the other actors. But as the chord diagram shows, ILKO also addressed CCC 113 and CCC 110. ILKO was in charge of the operation and provided the others with critical information. ILB was also active. The fire and rescue services hold the responsibility for the operation until the police are on site. ILKO got updated information until the time they were present.

There are several categories used in the alert phase; where "confirmation" represents $25 \%$ of the messages. As the bar chart presents, the messages are concerning several features regarding the agencies' SA. The categories "action", "action plan" and "location" are all representing an increasing SA based in the category "common understanding", representing that information exchanged in the BAPS call group was confirmed and understood by all agencies. One could interpret this as if all agencies in this phase were on the alert and followed the procedure for confirming.

The high percent of the category "confirmation" related to the confirmation that they heard and understood messages in the other categories. The "situation reports" would typically be communicated in the different internal-agency call groups which provide the agency-specific CCCs important information due to their profession.

\section{Escalated phase (10:30-11:00)}

In this phase, the number of messages was 20. All the agencies were active in BAPS, but ILB was far more active than the rest (Figure 4). In this phase, the operative units on site prepared themselves on the most resource-intensive incident, and the fire and rescue services had many tasks concerning the victims in the water. At this time, they would need as much information as possible. The situation was chaotic, which could explain the high frequency of "requests" and "situation reports". In practice, these types of messages contain requests of updated and/or more information, resources or support. We can also observe that the category "offer resources" is present, which implies that the stakeholders comprehended the situation. Thus, they can anticipate that the situation required more resources than the current state. The lack of "confirmation" can be a result of the busy situation where the actors had a lot going on both on site and in other call groups. As one stakeholder characterized the situation; "Simply a mental overload" [Stakeholder].
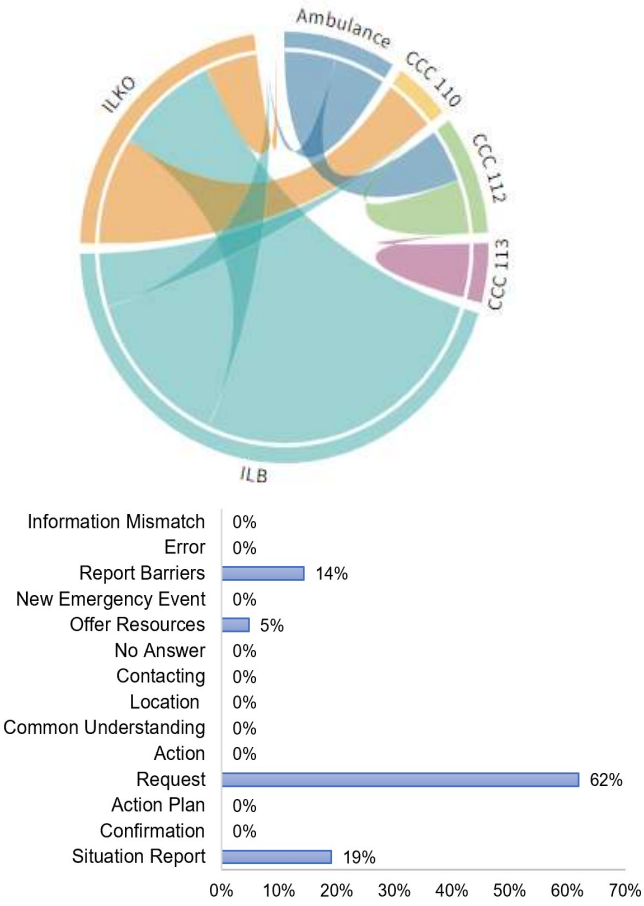

\section{Figure 4 Multi-agency interactions (upper) and information being exchanged (bottom), 10:30-11:00}

\section{Response phase (11:00-13:00)}

In this phase, the number of messages was 26 . The actors were working with agency-specific tasks and started to get an overview of the situation. As this was an act of terror, the police had a major responsibility to make the situation safe for both the collaborative agencies and the civil people present at the emergency site. This can explain why ILKO stands for most of the communication in BAPS as can be observed in the chord diagram (Figure 5). The terrorist was not arrested yet in this phase. All communications were in the category "Situation Reports". It shows that the use of BAPS is for building a COP by providing all agencies in the call group with information that is seen as common information needs. The lack of confirmation might have several reasons; firstly ILKO, ILB and ILH were all located at the assembly place for injured and deceased and did not need to use BAPS to confirm. They only used the call group for providing other actors with information. Secondly, the agencies might use the internal agency call groups for both communication and confirmation. Third, the actors were too busy handling the mass causalities for confirming.

Ideally, the "situation reports" should be confirmed by all agencies in BAPS. The lack of this can be explained by the assumption that the messages are not as critical as in the previous phases. It might also be caused by the 
professional culture and needs more attention. As one actor stated after seeing the results; "Clearly we must repeat our messages when we don 't get confirmation" [Stakeholder].
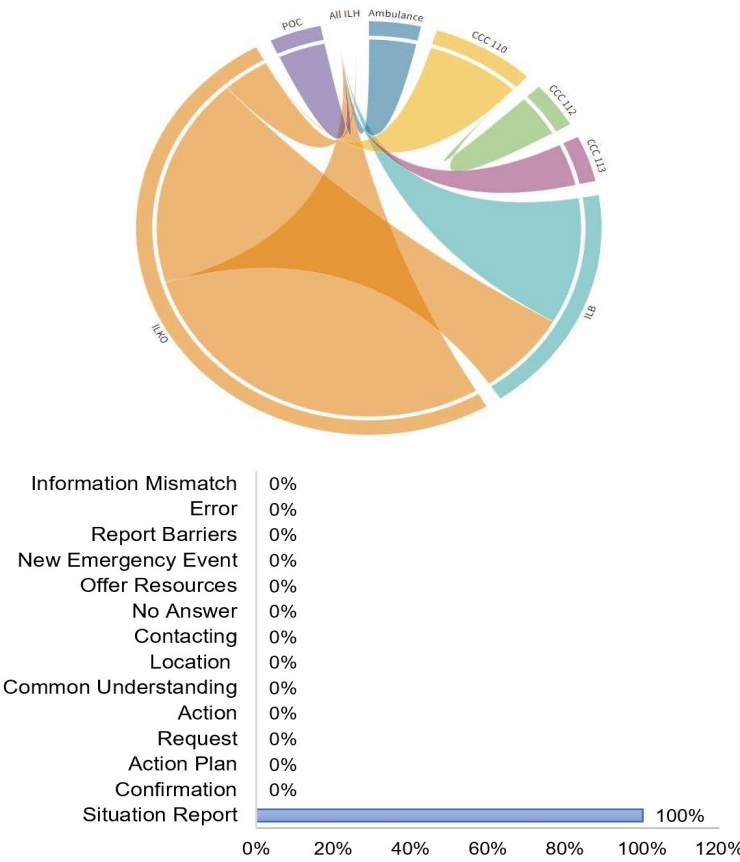

Figure 5 Multi-agency interactions (upper) and information being exchanged (bottom), 11:0013:00

\section{Discussion}

The results for all phases in the operation can provide an overall picture of the collaborative communication for building a COP. In the alert phase, a diversity of categories is being exchanged and the category "common understanding" shows that most of the information is understood by all stakeholders. It seems like the building of a COP is effective in the alert phase. The maintenance of the COP in the next phases (escalated and response phase) is less obvious. In the escalated phase, the situation was chaotic, and the stakeholders struggled to maintain a COP by using the category "request" most frequently. In the response phase, the stakeholders gained more control and provided each other with information. If this means that they maintained a COP is hard to conclude on, because of the absence of the "confirmation" category. This should ideally have been validated through retrospective interviews with stakeholder. Nevertheless, based on the observations, stakeholders' comments and the messages ' content, there is reason to believe that a COP was established in the two last phases. If the COP was absent, we assume the categories "request", "contacting" and "information mismatch" would have been used to some extent.

It is important to consider the fact that this is based on an exercise, which despite being planned to be as realistic as possible does not necessarily echo a real event. Exercises are fictitious and constructed and cannot provide the same effects as a real event, because of the participants' awareness that it is not real [25]. Furthermore, this case was an act of terror with multiple incidents, which represents an extraordinary situation. Because of this, the communication in BAPS does not mirror an ordinary multi-agency emergency operation. Nevertheless, this case was used for developing the categories and a methodology to analyze COP which we argue can be reusable in other full-scale exercises and evaluation after real events. Several of the features of the COP (table 1) can be identified in the analysis. Firstly, different levels of SA within the agencies can be observed through the categories "common understanding", "action" and "action plan". These categories indicate the actors 'perception of elements in the environment and that they comprehend the current status.

The fact that these categories are frequently used in the alert phase can demonstrate that the agencies' communication embraces several important features of a COP. For instance, the actors create SA (feature 1) and by sharing information (feature 3 and 5) they depict knowledge on each other's operational modus (feature 2 ) in the alert phase of this exercise. In the escalated phase the situation appeared as chaotic, and the high frequency of the "request" category can show that the agencies know the others' capabilities (feature 2) and requests for information or some sort of action. The last phase clearly reveals communication of information that is assumed to be important for the collaborative agencies (feature 3 and 5) by offering each other "situation reports". Regarding the harmonized terminology and standardized framework (feature 4 and 6) post hoc analysis of audio-logs provide a good opportunity to investigate this, but in that case, it would be necessary to compare the communication to the standards being used. In this case study, these standards do not exist in any textual documents. To analyze this, interviews with key stakeholders had to be required.

The first responder agencies have pre-defined tasks and goals which means that the messages` content and purpose are relevant for several different operations and can therefore be reusable for different settings. The audio-logs from emergency operations provides access to the actual real-time communication during the operation including the timeline. This gives the opportunity to capture the detailed information being exchanged in different stages of the operation. The fact that the actors use other ways to communicate internally 
in their associated agency and one-to-one conversations in the NPSN poses a challenge related to getting the whole picture. Even if the BAPS call group exists for collaborative communication, some of this information is then taking place outside this call group. Other imaginable limitations are the possibility of missing tracks in audio-logs, legal challenges related to getting access to audio-logs from real events and the nearly unavoidable requirement of the basic knowledge of this sort of emergency management operations. However, if the goal is to identify important features in one particular area, audio-logs provide real-time communication and the actual timeline in the operation.

\section{Conclusions and Future Work}

By using the important features for a COP, it is possible to evaluate the achievement and maintenance of COP during an emergency operation. The features are (1) Creation and maintenance of different levels of SA within the involved agencies (2) Knowledge of each other's operational modus (3) Effective and timespecific communication on important static and dynamic environmental features, shared elements and common critical cues (4) harmonized terminology (5) Sharing useful comprehension of the current situation and actions/action planning important for the collaboration, and (6) Follow a standardized framework for the communication. The categories developed in this case study aim to be reusable for post hoc analysis of the real-time communication related to establishing a COP in similar cases. We argue that this methodology can be an important supplement to textual reports and retrospective interviews for future evaluations of both full-scale exercises and real events.

The study's findings may inspire stakeholders and other researchers to further investigate the important features of a COP in exercises and real events, and use audio-logs and categories of messages to elicit a dynamic development of a COP. Currently, this methodology will be validated further in different scenarios. This can be achieved by applying the audio$\log$ analysis in other exercises as supplementation for other evaluation methods.

\section{References}

[1] KoKom, Manual, communication and collaboration in emergency medical situations Bergen: KoKom, 2018.

[2] L. K. Comfort, K. Ko, and A. Zagorecki, "Coordination in rapidly evolving disaster response systems: The role of information," American Behavioral Scientist, vol. 48, no. 3, pp. 295-313, 2004.

[3] N. Bharosa, J. Lee, and M. Janssen, "Challenges and obstacles in sharing and coordinating information during multi-agency disaster response: Propositions from field exercises," Information Systems Frontiers, vol. 12, no. 1, pp. 49-65, 2010.

[4] (2012). Report from the 22 July -commission [Online] Available:

https:/www.regjeringen.no/contentassets/bb3dc76229c64735b 4f6eb4dbfcdbfe8/no/pdfs/nou201220120014000dddpdfs.pdf

[5] D. A. Klima et al., "Full-scale regional exercises: closing the gaps in disaster preparedness," Journal of Trauma Acute Care Surgery, vol. 73, no. 3, pp. 592-598, 2012.

[6] M. C. Alkin and S. M. Taut, "Unbundling evaluation use," Studies in Educational Evaluation,, vol. 29(1), 2003.

[7] C. H. Weiss, "The interface between evaluation and public policy," Evaluation, vol. 5, no. 4, pp. 468-486, 1999.

[8] A. Imoussaten, J. Montmain, and G. Mauris, "A multicriteria decision support system using a possibility representation for managing inconsistent assessments of experts involved in emergency situations," International Journal of Intelligent Systems, vol. 29, no. 1, pp. 50-83, 2014.

[9] Y. Ju and A. Wang, "Emergency alternative evaluation under group decision-makers: A method of incorporating DS/AHP with extended TOPSIS," Expert Systems with Applications, vol. 39, no. 1, pp. 1315-1323, 2012.

[10] D. Gryth et al., "Evaluation of medical command and control using performance indicators in a full-scale, major aircraft accident exercise," Prehospital

disaster medicine, vol. 25, no. 2, pp. 118-123, 2010.

[11] K. Steen-Tveit and J. Radianti, "Analysis of Common Operational Picture and Situational Awareness during Multiple Emergency Response Scenarios," in Proceedings of the 16th International Conference on Information Systems for Crisis Response and Management (ISCRAM 2019), 2019.

[12] R. Abbas, T. Norris, D. Parry, and eHealth, "Pinpointing what is wrong with cross-agency collaboration in disaster healthcare," The International Journal of Telemedicine vol. 6, pp. e3 (1-10), 2018.

[13] K. E. Weick and K. M. Sutcliffe, Managing the unexpected: Sustained performance in a complex world. John Wiley \& Sons, 2015.

[14] D. Bunker, L. Levine, and C. Woody, "Repertoires of collaboration for common operating pictures of disasters and extreme events," Information Systems Frontiers, vol. 17, no. 1, pp. 51-65, 2015.

[15] M. R. Endsley and M. M. Robertson, "Situation awareness in aircraft maintenance teams," International Journal of Industrial Ergonomics, vol. 26, no. 2, pp. 301-325, 2000.

[16] P. M. Salmon et al., "What really is going on? Review of situation awareness models for individuals and teams," Theoretical Issues in Ergonomics Science, vol. 9, no. 4, pp. 297-323, 2008.

[17] N. A. Stanton, P. M. Salmon, G. H. Walker, E. Salas, and P. A. Hancock, "State-of-science: situation awareness in individuals, teams and systems," Ergonomics, vol. 60, no. 4, pp. 449-466, 2017.

[18] M. R. Endsley, "Situation awareness misconceptions and misunderstandings," Journal of Cognitive Engineering Decision Making, vol. 9, no. 1, pp. 4-32, 2015.

[19] G. K. Edgar et al., "Quantitative Analysis of Situation Awareness (QASA): modelling and measuring situation awareness using signal detection theory," Ergonomics, vol. 61, no. 6, pp. 762-777, 2018. 
[20] M. R. Endsley, "Toward a theory of situation awareness in dynamic systems," Human factors vol. 37, no. 1, pp. 32-64, 1995.

[21] R. Valecha, "An Investigation of Interaction Patterns in Emergency Management: A Case Study of The Crash of Continental Flight 3407," Information Systems Frontiers pp. 1-13, 2019.

[22] M. R. Endsley and M. M. Robertson, "Team situation awareness in aviation maintenance," in Proceedings of the Human Factors and Ergonomics Society Annual Meeting, 1996, vol. 40, no. 21: SAGE Publications Sage CA: Los Angeles, CA, pp. 1077-1081.

[23] M. Endsley, "Toward a theory of situation awareness in dynamic systems," Human factors, vol. 37, no. 1, pp. 32-64, 1995.

[24] L. J. Sorensen and N. A. Stanton, "Keeping it together: The role of transactional situation awareness in team performance," International Journal of Industrial Ergonomics, vol. 53, pp. 267-273, 2016.

[25] J. M. Berlin and E. D. Carlström, "Collaboration exercisesthe lack of collaborative benefits," International Journal of Disaster Risk Science, vol. 5, no. 3, pp. 192-205, 2014.

[26] N. Kapucu, "Collaborative emergency management: better community organising, better public preparedness and response," Disasters, vol. 32, no. 2, pp. 239-262, 2008.

[27] L. Comfort and N. Kapucu, "Inter-organizational coordination in extreme events: The World Trade Center attacks, September 11, 2001," Natural hazards, vol. 39, no. 2, pp. 309-327, 2006.

[28] D. A. McEntire, "Coordinating multi-organisational responses to disaster: lessons from the March 28, 2000, Fort Worth tornado," Disaster Prevention Management: An International Journal, vol. 11, no. 5, pp. 369-379, 2002.

[29] R. W. Perry, "Emergency operations centres in an era of terrorism: Policy and management functions," Journal of Contingencies Crisis Management, vol. 11, no. 4, pp. 151159, 2003.

[30] W. Smith and J. Dowell, "A case study of co-ordinative decision-making in disaster management," Ergonomics, vol. 43, no. 8, pp. 1153-1166, 2000.

[31] K. Banipal, "Strategic approach to disaster management: lessons learned from Hurricane Katrina," Disaster Prevention and Management: An International Journal, vol. 15, no. 3, pp. 484-494, 2006.

[32] A. Blandford and B. W. Wong, "Situation awareness in emergency medical dispatch," International journal of human-computer studies, vol. 61, no. 4, pp. 421-452, 2004.

[33] T. Norri-Sederholm, M. Joensuu, and A.-M. Huhtinen, "Ensuring Information Flow and the Situation Picture in Public Safety Organisations' Situation Centres," in European Conference on Cyber Warfare and Security, 2017: Academic Conferences International Limited, pp. 267-273.

[34] P. Salmon, N. Stanton, D. Jenkins, and G. Walker, "Coordination during multi-agency emergency response: issues and solutions," Disaster Prevention and Management: An International Journal, vol. 20, no. 2, pp. 140-158, 2011.

[35] P. Bindl, J, , "Does a Common Operational Picture Result in Common Understanding of the Battlespace? ," Naval War College 2005. [Online]. Available: https://apps.dtic.mil/dtic/tr/fulltext/u2/a425946.pdf
[36] R. Valecha, H. R. Rao, S. Upadhyaya, and R. Sharman, "An Activity Theory Approach to Modeling Dispatch-Mediated Emergency Response," Journal of the Association for Information Systems, vol. 20, no. 1, pp. 33-57, 2019.

[37] C. Reuter, V. Pipek, T. Wiedenhoefer, and B. Ley, "Dealing with terminologies in collaborative systems for crisis management," in Proceedings of the 9th International ISCRAM Conference 2012.

[38] M. Snaprud, J. Radianti, and D. Svindseth, "Better access to terminology for crisis communications," in International Conference on Information Technology in Disaster Risk Reduction, 2016: Springer, pp. 93-103.

[39] S. E. Wright and G. Budin, Handbook of terminology management: application-oriented terminology management. John Benjamins Publishing, 2001.

[40] A. H. Tapia and K. Moore, "Good enough is good enough: Overcoming disaster response organizations' slow social media data adoption," Computer supported cooperative work, vol. 23, no. 4-6, pp. 483-512, 2014.

[41] G. M. Karagiannis and C. E. Synolakis, "Collaborative incident planning and the common operational picture," in International Conference on Dynamics of Disasters, 2016: Springer, pp. 91-112.

[42] M. Janssen, J. Lee, N. Bharosa, and A. Cresswell, "Advances in multi-agency disaster management: Key elements in disaster research," Information Systems Frontiers, vol. 12, no. 1, pp. 1-7, 2010.

[43] E. A. Borglund, "The role of artefacts in creating a common operational picture during large crises," in 14th International Conference on Information Systems for Crisis Response and Management, ISCRAM, 2017, vol. 2017: ISCRAM, pp. 191203.

[44] J. Wolbers and K. Boersma, "The common operational picture as collective sensemaking," Journal of Contingencies Crisis Management, vol. 21, no. 4, pp. 186-199, 2013.

[45] L. I. Magnussen, E. Carlstrøm, J. L. Sørensen, G.-E. Torgersen, E. F. Hagenes, and E. Kristiansen, "Learning and usefulness stemming from collaboration in a maritime crisis management exercise in Northern Norway," Disaster Prevention Management, vol. 27, no. 1, pp. 129-140, 2018.

[46] M. Sommer, G. S. Braut, and O. Njå, "A model for learning in emergency response work," International Journal of Emergency Management, vol. 9, no. 2, pp. 151-169, 2013.

[47] J. M. Berlin and E. D. Carlström, "Collaboration Exercises: What Do They Contribute? -A Study of Learning and Usefulness," Journal of Contingencies Crisis Management, vol. 23, no. 1, pp. 11-23, 2015.

[48] (2018). Common rules for the use of Norwegian Public Safety Network [Online] Available: https://www.politiet.no/globalassets/05-om-oss/03strategier-og-planer/sambandsreglement-for-nodetatene.pdf

[49] (2017). The Use of Norwegian Public Safety Network [Online] Available: https://www.nodnett.no/globalassets/nodnett-i-bruk.pdf

[50] A. De Moor, "Collaboration patterns as building blocks for community informatics," in Proc. of the 6th Prato Community Informatics Research Network Conference, Prato, Italy, 2009.

[51] B. Bygstad and B. E. Munkvold, "Exploring the role of informants in interpretive case study research in IS," Journal of Information Technology, vol. 26, no. 1, pp. 32-45, 2011. 